\title{
Influences of acute and/or chronic exercise on human immunity: third series of scientific evidence
}

\author{
Yong-Seok Jee (iD https://orcid.org/0000-0001-6797-0843
}

When exercise is initiated, the sympathetic nerve fibers are stimulated in the brain to raise cardiac output and release catecholamine from the adrenal medulla. The brain also activates the neuroendocrine system to produce the adrenocorticotropic hormone from the hypothalamic-pituitary-adrenal axis and for the adrenal cortex to release cortisol. With the increase in cardiac output, cortisol and catecholamine are transferred to cells that have a modified effector phenotype. The effectors remove micromaterials and cytokine expressions that affect organs as they are moved to the tissues with other immune mediators (heat shock proteins, chemokines, and cytokines). Physical activity affects human immunity, but the extent of the effects depends on whether it is acute or chronic. Acute exercise is defined as a single session of exercise, and chronic exercise is characterized by a very demanding workout routine that can involve intense exercise on a daily basis. Factors that influence immune response and adaptation are being investigated to gain a better understanding of uncovering a vaccine type of effect from acute and chronic exercise. This requires understanding the complex process of the immune system's response to vaccination before investigating the potential of changing the response through exercise.

The three kinds of human immunity include innate, adaptive, and passive. Since passive immunity is temporary and comes from other sources, this editorial will focus only on innate and adaptive immunity. Innate immunity is what people are born with, which provides general protection. It first detects invaders such as toxins, bacteria, and viruses and then activates cells to attack and destroy them. Adaptive immunity, which involves the lymphocytes, develops over time through exposure to various diseases, including immunization from vaccination. An immunological memory is created after initially responding to a particular pathogen, which enables adaptive immunity to respond more effectively when encountering the same pathogen in the future. Vaccination follows the same process of acquiring immunity (Kurosaki et al., 2015). The innate immune system consists of leukocytes with a nonspecific response. The adaptive immune system consists of T cells, B cells, and antigens with a specific response. Natural killer (NK) cells are lymphocytes that are a part of the innate immune system. Instead of directly attacking pathogens, they destroy host cells that have been compromised, such as virus-infected cells and tumor cells.

Physical exercise is an activity that involves moving the body to improve physical fitness, health, and wellness. Developing athletic skills, losing weight, increasing muscle strength, improving the cardiovascular system, and enjoyment are some of the various reasons for exercising. Exercising on a regular basis strengthens the immune system and can serve to prevent many kinds of diseases. A temporary suppression of the immune system can result from long durations of intense exercise. Reduced neutrophil phagocytic function and lower counts of lymphocyte and NK cells have resulted 2-24 hours after protracted intense exercise (Kakanis et al., 2010), which can compromise immune function and increase susceptibility to infection. On the other hand, the acute-stress induced immune-enhancement hypothesis states that exercising moderately can improve immune response (Edwards et al., 2007). Research studies involving chronic exercise effects on the body's response to vaccination have consistently shown that older adults who exercise moderately lead to improved immune function (Grant et al., 2008; 
Keylock et al., 2007; Kohut et al., 2004; Smith et al., 2004; Yang et al., 2007). Studies involving young adult subjects are relatively limited with only one study that provides evidence that increased exercise leads to improved responses to vaccination (Smith et al., 2004). The research studies mentioned above strengthen the hypothesis that immune responses to vaccination can be enhanced after only one bout of exercise performed at moderate intensity. In summary, acute exercise may enhance T-cell activity while chronic exercise may lead to reduced T-cell activity. However, both acute and chronic exercises resulted in increased counts of B cells.

The first series is presented in J Exerc Rehabil 2019;15(3):339340, available from: https://doi.org/10.12965/jer.1938302.151

The second series is presented in J Exerc Rehabil 2020;16(2): 113-114, available from: https://doi.org/10.12965/jer.2040178. 089

\section{CONFLICT OF INTEREST}

No potential conflict of interest relevant to this article was reported.

\section{REFERENCES}

Edwards KM, Burns VE, Carroll D, Drayson M, Ring C. The acute stressinduced immunoenhancement hypothesis. Exerc Sport Sci Rev 2007; 35:150-155.

Grant RW, Mariani RA, Vieira VJ, Fleshner M, Smith TP, Keylock KT, Lowder TW, McAuley E, Hu L, Chapman-Novakofski K, Woods JA.
Cardiovascular exercise intervention improves the primary antibody response to keyhole limpet hemocyanin (KLH) in previously sedentary older adults. Brain Behav Immun 2008;22:923-932.

Kakanis MW, Peake J, Brenu EW, Simmonds M, Gray B, Hooper SL, Marshall-Gradisnik SM. The open window of susceptibility to infection after acute exercise in healthy young male elite athletes. Exerc Immunol Rev 2010;16:119-137.

Keylock KT, Lowder T, Leifheit KA, Cook M, Mariani RA, Ross K, Kim K, Chapman-Novakofski K, McAuley E, Woods JA. Higher antibody, but not cell-mediated, responses to vaccination in high physically fit elderly. J Appl Physiol (1985) 2007;102:1090-1098.

Kohut ML, Arntson BA, Lee W, Rozeboom K, Yoon KJ, Cunnick JE, McElhaney J. Moderate exercise improves antibody response to influenza immunization in older adults. Vaccine 2004;22:2298-2306.

Kurosaki T, Kometani K, Ise W. Memory B cells. Nat Rev Immunol 2015; 15:149-159.

Smith TP, Kennedy SL, Fleshner M. Influence of age and physical activity on the primary in vivo antibody and T cell-mediated responses in men. J Appl Physiol (1985) 2004;97:491-498.

Yang Y, Verkuilen J, Rosengren KS, Mariani RA, Reed M, Grubisich SA, Woods JA. Effects of a Taiji and Qigong intervention on the antibody response to influenza vaccine in older adults. Am J Chin Med 2007;35: 597-607.

Research Institute of Sports and Industry Science, Hanseo University 46 Hanseo 1-ro, Haemimyeon, Seosan 31962, Korea E-mail: jeeys@hanseo.ac.kr 